\title{
Efficacy of 104-week Telbivudine-based optimization strategy in patients with HBeAg-negative chronic hepatitis B virus infections
}

Weiqiang Gan ${ }^{1+}$, Jianguo $\mathrm{Li}^{1+}$, Chunlan Zhang ${ }^{2}$, Xuefu Chen ${ }^{3}$, Chaoshuang Lin ${ }^{1 *}$ and Zhiliang Gao ${ }^{1 *}$

\begin{abstract}
Background: Evaluate the safety and efficacy of 104-week regimen of Telbivudine(LdT)-based optimization strategy for Chinese patients who have chronic hepatits B(CHB) with HBeAg-negative.

Methods: This multi-center, open-label, prospective study enrolled $108 \mathrm{HBeAg-negative} \mathrm{CHB}$ patients who received LdT (600 mg/day) for 24 weeks, Adefovir (ADV) was added if HBV DNA remained detectable at week 24, otherwise LdT was maintained to use until 104 weeks. HBV DNA, alanine amino transferase (ALT), hepatitis B surface antigen(HBsAg), creatinine kinase(CK), and estimated glomerular filtration rate (eGFR) were measured, safety was assessed.

Results: Eighty-eight patients (81\%) had HBV-DNA undetectable at 24 weeks and maintained to receive LdT monotherapy until 104 weeks, whereas the other 20 patients had HBV-DNA detectable and ADV was used in combination. For all patients, $72 \%$ of patients reached ALT normalization at 24 weeks, which increased to $80 \%$ at 52 weeks and 104 weeks, respectively.. $81 \%$ of total patients had undetectable HBV-DNA at 24 weeks, $92 \%$ at 52 weeks, and $94 \%$ at 104 weeks. The HBsAg titre declined steadily from baseline to 104 weeks (3.62 vs. $2.98 \log 10 \mathrm{IU} / \mathrm{mL}, p<$ 0.05), and the eGFR increased steadily from baseline to 104 weeks (92.9 vs. $104.4 \mathrm{~mL} / \mathrm{min} / 1.73 \mathrm{~m}^{2}, p<0.05$ ). Although 79 patients (73\%) had at least one time of elevated CK, most of these patients had CK elevated in Grade $1 / 2$.
\end{abstract}

Conclusions: LdT was well tolerated and effective, and 94\% of patients achieved virological suppression after 104 weeks.

Trial registration: This study was registered in clinicaltrials.gov on January 31, 2012 and the ID No. was NCT01521 975.

Keywords: Chronic hepatitis B, eGFR, HBeAg, Telbivudine

\footnotetext{
*Correspondence: Ichaosh@mail.sysu.edu.cn; gzhiliang0@163.com; gaozhl@mail.sysu.edu.cn

tWeiqiang Gan and Jianguo Li contributed equally to this work. 'Department of Infectious Disease, The Third Affiliated Hospital of Sun Yat-sen University, 600 Tianhe Road, Tianhe District, Guangzhou 510630, Guangdong Province, China

Full list of author information is available at the end of the article
}

(c) The Author(s). 2020 Open Access This article is licensed under a Creative Commons Attribution 4.0 International License, which permits use, sharing, adaptation, distribution and reproduction in any medium or format, as long as you give appropriate credit to the original author(s) and the source, provide a link to the Creative Commons licence, and indicate if changes were made. The images or other third party material in this article are included in the article's Creative Commons licence, unless indicated otherwise in a credit line to the material. If material is not included in the article's Creative Commons licence and your intended use is not permitted by statutory regulation or exceeds the permitted use, you will need to obtain permission directly from the copyright holder. To view a copy of this licence, visit http://creativecommons.org/licenses/by/4.0/ The Creative Commons Public Domain Dedication waiver (http://creativecommons.org/publicdomain/zero/1.0/) applies to the data made available in this article, unless otherwise stated in a credit line to the data. 


\section{Background}

Chronic hepatitis B virus (HBV) infection is a major public health problem worldwide. An estimated 240 million people have chronic HBV infections [1], and about $75 \%$ of them reside in the Asia-Pacific region [2]. HBV infection causes more than one million deaths every year due to acute or chronic outcomes, including end-stage liver disease, cirrhosis, and hepatocellular carcinoma (HCC) [3, 4]. Therefore, more aggressive antiviral therapies are needed to manage and control it.

In recent decades, regulatory agencies have approved several antiviral agents for HBV infections treatment, including interferon and several oral drugs (such as telbivudine $[\mathrm{LdT}]$, lamivudine [LAM], tenofovir [TDF], entecavir, and adefovir [ADV]) [5-7]. Among the oral antiviral agents, several major guidelines for chronic hepatitis $\mathrm{B}$ recommended entecavir and tenofovir as first-line therapy for $\mathrm{CHB}[3,8,9]$. However, tenofovir is not available but entecavir is not affordable in some lowincome countries, which limited the first-line therapy options for many patients. In recent years, with the listing of tenofovir, the price of entecavir in China has dropped significantly.

$\mathrm{LdT}$ is a $\beta$-L-nucleoside analog which is chose to treat patients with chronic HBV infections who have active viral replication and abnormal levels of ALT. LdT has better efficacy than lamivudine and has a higher $\mathrm{HBeAg}$ seroconversion rate in $\mathrm{HBeAg}$-postive $\mathrm{HBV}$ patients compared with other oral antiviral agents [10]. ,However, there has few researches regarding the efficacy of LdT in HBV patients with HBeAg-negative. This study evaluated the safety and efficacy of LdT -Based Optimization Strategy in patients with HBV who were HBeAg-negative.

\section{Methods}

\section{Study design}

This was a prospective, 104-week, multicenter, singlearm, open-label, phase IV, long-term trial that enrolled 154 patients from April 2012 to July 2014 among three hospitals in Guangdong Province, China (The Third Affiliated Hospital of Sun-Yet-Sen University, Guangdong General Hospital, and The Eighth People's Hospital of Guangzhou). All enrolled patients received sequential therapy with supportive care during the whole study. Each patient received single oral tablet of LdT $(600 \mathrm{mg})$ daily for the first 24 weeks. ADV was added if HBV DNA remained detectable at week 24, otherwise LdT was maintained to use until 104 weeks. Patients received LDT monotherapy with virological breakthrough were added with adefovir, otherwise TDF was chose as rescue treatment. Clinical, laboratory, and adverse event assessments were collected every 12 or 16 weeks from baseline (week 0) to week 104. This study conformed to the ethics principles of the Declaration of Helsinki and Good Clinical Practice and according to the regulatory requirements of China. It also obtained ethical approval from the Institutional Review Board (IRB) of the Third Affiliated Hospital of Sun-Yat-Sen University, IRB of Guangdong General Hospital and IRB of the Eighth People's Hospital of Guangzhou. Written informed consent have been obtained from all participants. This study was registered in clinicaltrials.gov on January 31, 2012 and the ID No. was NCT01521975.

\section{Inclusion and exclusion criteria}

Inclusion criteria: (1) patients had $\mathrm{HBeAg}$-negative $\mathrm{CHB}$; (2) patients aged 18-65 years-old; (3) patients had detectable HBV S-antigen (HBsAg) at screening visit, with serum HBV-DNA level above $4 \log _{10} \mathrm{IU} / \mathrm{mL}$; (4) patients had ALT level at 2 to 10 -fold above the upper limit than normal (ULN) of $35 \mathrm{U} / \mathrm{L}$; (5) patients had ALT level at less than 10-fold ULN if they were complicated with liver cirrhosis. Exclusion criteria: (1) patients had coinfection with hepatitis $C$ virus, hepatitis $D$ virus, or HIV, decompensated liver cirrhosis or HCC; (2) patients received nucleoside analogs, immunosuppressive drugs, or other antiviral drugs; (3) patients had history of tumor.

\section{Index detection}

HBV m quantitative time resolved fluorescence diagnostic kit was provided by Suzhou Xinbo Biotechnology Co., Ltd. (Suzhou, China) and analyzed by 1235 automatic time-resolved fluoroimmunoassay system (American PE company). HBV DNA quantitative detection kit was provided by Sun Yat sen University Da'an gene Co., Ltd. (Guangzhou, China) and analyzed by GeneAmp5700 fluorescent PCR detector (American PE company). Serum CK, creatine kinase, ULN, ALT and eGFR were detected by automatic biochemical analyzer with commercial kits (Nanjing Jiangcheng Bioengineering Institute, Nanjing, China).

\section{Efficacy assessment}

The primary endpoint was undetectable HBV-DNA (< $20 \mathrm{IU} / \mathrm{mL}$ ) at week 52 and 104. The secondary endpoint was ALT normalization at week 24, 52, and 104 and loss of HBsAg seroconversion at week 52 and 104. Virological breakthrough was also recorded.

\section{Safety assessment}

The safety assessment consisted of adverse events (AEs) monitoring from clinical and laboratory examinations and their relationships with this study, based on the investigators' assessment. The safety population included all patients who received at least one dose of the study medication (intention to treat [ITT] population) and had at least one post-baseline safety assessment. 


\section{Statistical analysis}

All statistical analyses were performed using SPSS (SPSS Statistics Version 19, IBM). Continuous variables were described as means and standard deviations (SD) and categorical variables (e.g. age and gender) as number and percentages. Significant differences between groups were evaluated using one-way analysis of variance. Differences between groups were considered statistically significant at $P<0.05$.

\section{Results}

\section{Patient enrollment and baseline characteristics}

The trial initially enrolled 154 patients, 66 patients still had detectable HBV DNA at week 24, who were introduced the Roadmap strategy to all of the patients and suggested to add ADV, 25 patients rejected the suggestion for higher cost, the other 21 patients declined the strategy considering more side effects, these 46 patients were excluded from the study. The other 20 patients received ADV add-on therapy, totally 108 patients were eligible for efficacy analysis finally. The mean baseline level of HBV-DNA was $6.0 \log _{10} \mathrm{IU} / \mathrm{mL}$ and the mean level of ALT was $135 \mathrm{U} / \mathrm{L}$ (Table 1).

\section{Efficacy: biochemical response}

After 12 weeks of LdT therapy, 70 patients (65\%) had ALT levels below the ULN (Fig. 1), and the ALT declined by an average $( \pm \mathrm{SD})$ of $102 \pm 134 \mathrm{U} / \mathrm{L}$ relative to baseline $(p<0.05)$. The number of patients with ALT levels below the ULN continued to increase throughout the study period (week $24: n=78,72 \%$; week $52: n=86$, 80\%; week 104: $n=86,80 \%)$.

\section{Efficacy: virological response}

At week 12, 81out of 154 (53\%) patients had undetectable HBV-DNA $(<20 \mathrm{IU} / \mathrm{mL})$, and the HBV-DNA declined an average of $5.1 \log _{10} \mathrm{IU} / \mathrm{mL}$ (range: 4.8 to 5.5 $\log _{10} \mathrm{IU} / \mathrm{mL}, p<0.05$ ) (Fig. 2). At week 24, 88 out of 154 (57\%) patients had undetectable HBV-DNA. Sixty-six patients had detectable HBV-DNA and ADV was added to 20 patients, the other 46 patients were excluded from the Roadmap study and the subsequent treatment and observation. The virological response using LdT-based

Table 1 Baseline demographic and disease characteristics of CHB patients treated with telbivudine $(n=108)$

\begin{tabular}{ll}
\hline Characteristic & N (SD or \%) \\
\hline Age, years & $40( \pm 10)$ \\
Sex, male, $n(\%)$ & $87(81 \%)$ \\
HBV DNA, $\log _{10} \mid \mathrm{U} / \mathrm{mL}$ & $6.0( \pm 1.3)$ \\
HBsAg titre, $\log _{10} \mathrm{IU} / \mathrm{mL}$ & $3.6( \pm 0.5)$ \\
ALT, U/L & $135( \pm 131)$ \\
CK, U/L & $129( \pm 61)$ \\
\hline
\end{tabular}

optimization strategy was high throughout the study period (week 36: 96\%, 104/108; week 52: 92\%, 99/108; week 102: 94\%).

\section{Efficacy: serologic response}

There was a significant decrease in the mean HBsAg titre from baseline until week 24 (3.62 vs. $3.38 \log _{10} \mathrm{IU} /$ $\mathrm{mL} ; p<0.001$ ) (Fig. 2). This decline tendency continued to week $52\left(3.18 \log _{10} \mathrm{IU} / \mathrm{mL}, p<0.001\right)$ and week 104 $\left(2.98 \log _{10} \mathrm{IU} / \mathrm{mL}, p<0.001\right)$. Only one patient experienced HBsAg loss without HBsAg seroconversion.

\section{Virological breakthrough}

A total of 6 patients (5.6\%) had virological breakthroughs during the 104-week therapy period (Table 2). Among these 6 patients, 1 had virological breakthrough at week 36, 5 had breakthroughs at week 52. M204V mutation was found in 3 patients, L180M mutation in 1 patient and M204I mutation in 2 patients. We switched 3 of these 6 patients to TDF, then these 3 patients had undetectable HBV-DNA after 24 weeks. ADV was added to the other 3 patients, 2 of them had undetectable HBV DNA after 24 weeks, and 1 patient had undetectable after 48 weeks.

\section{Changes in eGFR}

The baseline eGFR was $92.9 \mathrm{~mL} / \mathrm{min} / 1.73 \mathrm{~m}^{2}$, and this increased to $97.7 \mathrm{~mL} / \mathrm{min} / 1.73 \mathrm{~m}^{2}$ at week $24(p<0.001)$, then up to $104.4 \mathrm{~mL} / \mathrm{min} / 1.73 \mathrm{~m}^{2}$ at week $104(p<$ 0.001) (Fig. 3).

\section{Safety evaluation}

A total of $45(29 \%)$ patients reported AEs who were related to the study medication, but with no deaths. Overall, there were 6 serious AEs (3.9\%): pneumonia for 3 patients, urinary tract infections for 2 patients, and gastric ulcer for 1 patient. All of these serious AEs were resolved with supplemental treatments, and cessation of LdT therapy was not necessary, so we considered that none of them was related to the study medication.

An increasing number of patients had elevated serum CK during the study period (Table 3). A total of 79 (51\%) patients had CK elevation in Grade 1 at least during the study period, but most of them only had elevations in Grade 1/2. Although 10 of 108 patients (9\%) had CK elevation in Grade 3/4, all of them had these elevations during only one visit. The patients who had CK elevation in Grade 4 at week 52 exercised the day before blood was drawn, and he returned to CK elevation in Grade 2 after 4 weeks. Among all 79 patients with elevated CK levels, 17 patients were complicated with myalgia that was resolved gradually. 


\section{ALT Normalization Rate}

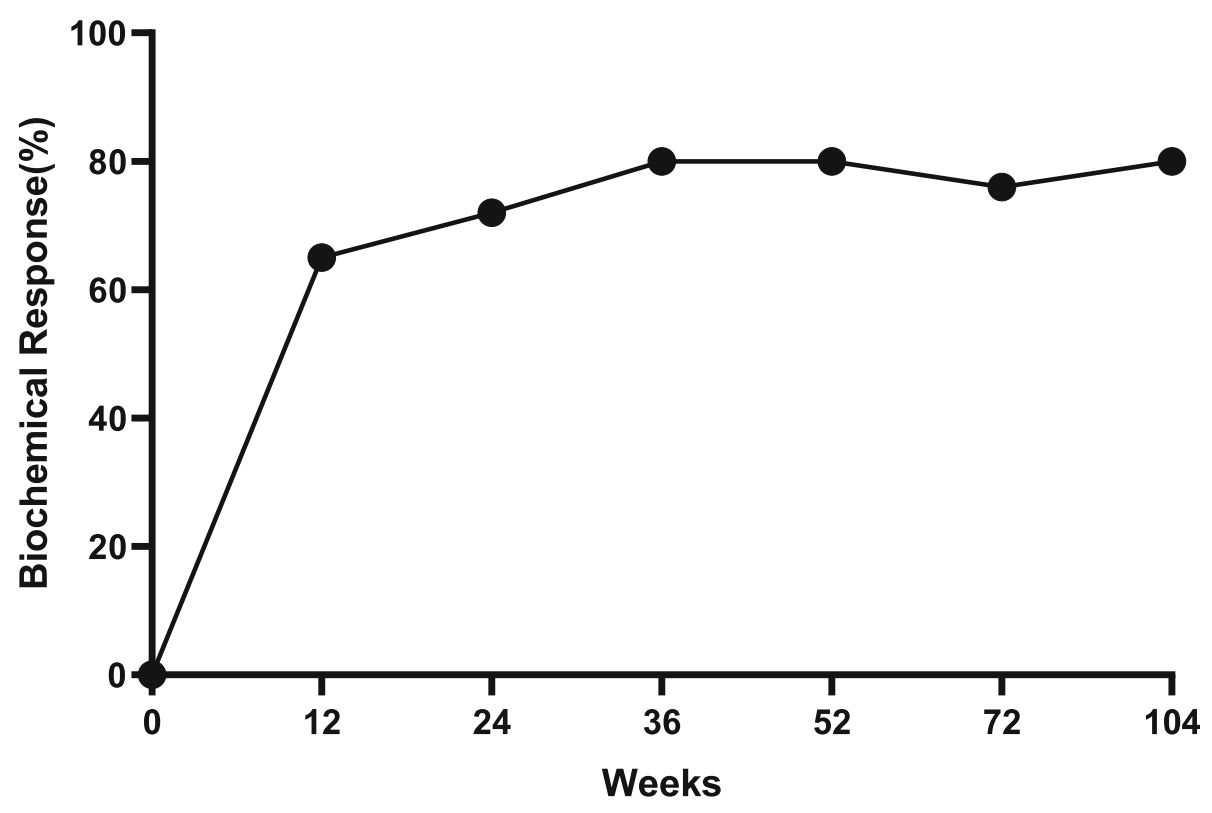

Fig. 1 ALT Normalization Rate

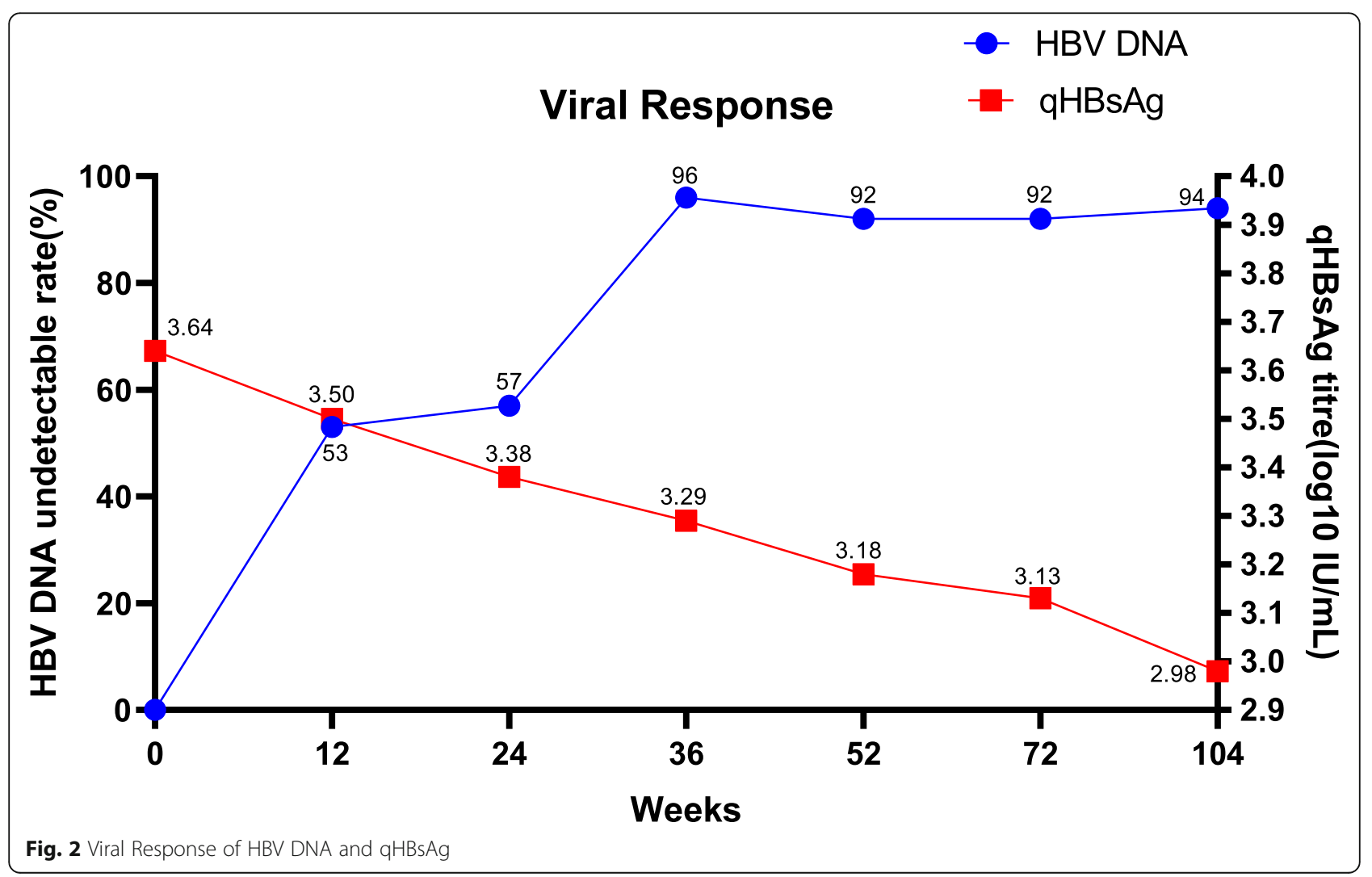


Table 2 Virological breakthrough during the study

\begin{tabular}{lllll}
\hline Patient $\left(\mathbf{P}^{\mathbf{n}}\right)$ & Group & Breakthrough time (Week) & Mutation & Rescue therapy \\
\hline$P^{1}$ & LDT & 36 & M204l & LDT+ADV \\
$P^{2}$ & LDT & 52 & M204l & LDT+ADV \\
$P^{3}$ & LDT & 52 & L180M & LDT+ADV \\
$P^{4}$ & LDT & 52 & M204V & LDT+ADV \\
$P^{5}$ & LDT + ADV & 52 & M204V & TDF \\
$P^{6}$ & LDT + ADV & 52 & & TDF \\
\hline
\end{tabular}

\section{Discussion}

Many major guidelines for liver diseases, including the American Association for the Study of Liver Diseases (AASLD) and the European Association for Study of the Liver (EASL), only recommend entecavir or tenofovir as first-line therapy for treatment patients with HBV [3]. However, many patients from the Asia-Pacific region do not have access to these drugs forced by money. Thus, lamivudine, LdT, and adefovir are still widely used in treatment of HBV.

The GLOBE study indicated that LdT had better efficacy than lamivudine in terms of virological response, serologic response, and drug resistance in $\mathrm{CHB}$ patients with $\mathrm{HBeAg}$-positive $[11,12]$. After treatment for 2 years in GLOBE study, $82 \%$ of patients had non-detectable viremia. After 104 weeks of LdT-based optimizedd strategy, our population had a higher response rate (94\%), although the research illustrated that response to entacavir was even greater (96.5\%) [13]. As a potent antiviral agent, LdT has proven efficacy in suppressing HBV replication, and has advantage in $\mathrm{HBeAg}$ seroconversion over other antiviral agents in HBeAg-positive patients with $\mathrm{CHB}$ [14]. However, few studies have examined the effect of LdT in HBeAg-negative patients with $\mathrm{CHB}$. Our results showed that LdT-based optimization strategy was effective, and $80 \%$ of patients turned to normal ALT levels and $94 \%$ patients became to undetectable HBV-DNA at week-104.

A major concern regarding LdT therapy had high rate of resistance. Liaw, et al. reported the overall resistance rate was $25.1 \%$ after 2 years of LdT treatment for $\mathrm{CHB}$ patients [12], and the resistance rate was $10.8 \%$ for HBeAg-negative patients. Combination therapy might reduce drug resistance. Liu, et al. reported the incidence of drug resistance was $4 \%$ by using LdT plus ADV at week $48,5.3 \%$ at week $96,10 \%$ at week 144 , and $11.6 \%$ at week 192 for $\mathrm{HBeAg}$-positive patients with $\mathrm{CHB}$ [15]. In order to decrease the resistance rate, we utilized a Roadmap strategy. The 2-year drug resistance rate was $5.6 \%$ in our trial, much lower than the related research

\section{eGFR}

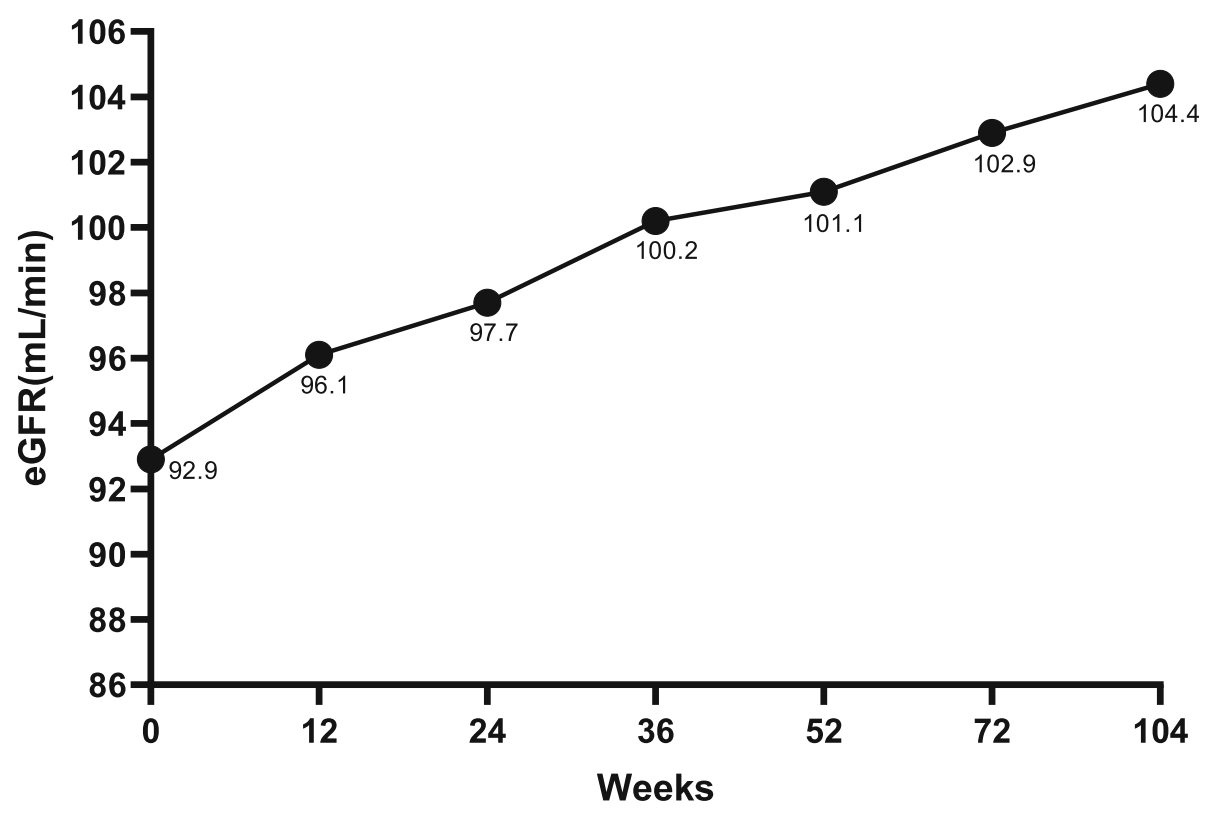

Fig. 3 eGFR levels 
Table 3 CK elevation during telbivudine treatment

\begin{tabular}{|c|c|c|c|c|c|c|c|}
\hline$\overline{C K}$ & Baseline & Week 12 & Week 24 & Week 36 & Week 52 & Week 72 & Week 104 \\
\hline Grade $1, \mathrm{n}$ & 14 & 22 & 26 & 29 & 38 & 31 & 42 \\
\hline Grade 2, n & 0 & 3 & 3 & 14 & 19 & 13 & 16 \\
\hline Grade $3, \mathrm{n}$ & 0 & 0 & 0 & 1 & 2 & 6 & 0 \\
\hline Grade 4, n & 0 & 0 & 0 & 0 & 1 & 0 & 0 \\
\hline Total, n & 14 & 25 & 29 & 44 & 60 & 50 & 58 \\
\hline
\end{tabular}

conclusions. We found that the accumulative incidence of drug resistance might increase with treatment duration, so more long-term data are needed in the future.

Another concern biomarker is CK elevation during LdT therapy, which have been reported in many previous studies [16, 17]. Chen, et al. studied $527 \mathrm{CHB}$ patients and reported that $60.91 \%$ of them had CK elevation [18], which was similar with our result (55\%). Few studies have reported the management and prognosis of CHB patients who had CK elevation in Grade 3/4 during LdT treatment, especially those who continued with this therapy. Our results reassuringly showed that when such patients continue LdT therapy, their CK levels would gradually normalize. Very few of our patients had musculoskeletal symptoms. These results implied that patients with CK elevation in Grade 3/4 might safely in continuous LdT therapy under monitoring closely.

HBsAg loss or seroconversion often leads to cessation of nucleoside treatment [3], and there contains special relationship of HBV genotypes and the rate of spontaneous or antiviral therapy-associated $\mathrm{HBeAg}$ seroconversion. For example, genotype $C$ patients endure delayed $\mathrm{HBeAg}$ seroconversion and thus have a longer duration of high viral load than genotype B patients. Therefore, genotype $\mathrm{C}$ patients are correspondingly more prone to develop advanced fibrosis, cirrhosis and HCC than genotype B patients. And the presence of HBV mutants, such as precore and basal core promoter mutations, may affect the response to antiviral therapy in $\mathrm{HBeAg}$ positive disease. Many studies demonstrated that HBsAg decreasing was related to better antiviral therapy outcome [19]. Our study showed that LdT-based optimization strategy could decrease the HBsAg level though no patients had loss of HBsAg. The duration of treatment in our study was only 2 years, so continued monitoring of the dynamics of $\mathrm{HBsAg}$ was necessary for longer treatment. Meanwhile, several biomarkers predicting $\mathrm{HBeAg}$ seroconversion have been identified. Such as the baseline total anti-HBc levels could predict $\mathrm{HBeAg}$ seroconversion in $\mathrm{HBeAg}$-positive $\mathrm{CHB}$ patients receiving antiviral therapy $[20,21]$. In addition, host genetic polymorphisms have been reported to predict response to pegylated interferon in HBeAg-positive patients [22]. And recent clinical trials revealed that patients receiving pegylated interferon combined or addon nucleos $(\mathrm{t})$ ide analogue had significantly higher $\mathrm{HBeAg}$ seroconversion rates than those receiving nucleos(t)ide analogue monotherapy [23, 24].

The quantitative detection of HBV serum markers and HBV DNA plays a complementary role in the diagnosis of HBV infection, which makes the diagnosis more accurate. It has been found that il-12a rs568408 is related to the seroconversion of Entecavir in the treatment of HBeAg. Recent studies have shown that IL-21 could promote the activation of various immune cell functions in the process of HBV infection. IL-21 gene polymorphism was related to HBV susceptibility. In addition, IL-21 expression was closely related to HBV genotype, HBV clearance, $\mathrm{HBeAg}$ seroconversion, HBV related cirrhosis, liver failure, liver cancer and autoimmune dieases. $\mathrm{CHB}$ can lead to chronic kidney disease, because of the accumulation of immune compounds in kidney. Gane, et al. found that LdT might increase eGFR by $8.5 \%$ for $4-6$ years, and this effect was unrelated to its antiviral action [25], implying a direct influence of LdT to renal function. Our study also showed that LdT therapy improved eGFR. Thus, LdT might become a good treatment option for CHB patients, especially those with high risk of developing chronic kidney disease (i.e. those with high blood pressure or diabetes),

\section{Conclusion}

In conclusion, the current study showed that 104 week LdT-based optimization strategy was well-tolerated and effective in $\mathrm{HBeAg}$-negative $\mathrm{CHB}$ patients, and that most patients achieved virological suppression after 104 weeks.

\section{Abbreviations \\ CHB: Chronic hepatits B; ADV: Adefovir; ALT: Alanine amino transferase; HBsAg: Hepatitis B surface antigen; CK: Creatinine kinase; eGFR: Estimated glomerular filtration rate; HBV: Chronic hepatitis B virus; HCC: Hepatocellular carcinoma; LdT: Telbivudine; LAM: Lamivudine; TDF: Tenofovir; ETV: Entecavir; HBsAg: HBV S-antigen; ULN: Upper limit than normal; AEs: Adverse events; ITT: Intention to treat; AASLD: The American Association for the Study of Liver Diseases}

\section{Acknowledgements}

None.

Authors' contributions

GW collected, analysis data and wrote the manuscript. $L$ and ZC enrolled patients and prepared Figs. 1,2 and 3. CX enrolled patients and prepared 
Tables 1, 2 and 3. GZ enrolled patients and amended the manuscript. LC was responsible for the whole study and guided GW. The author(s) read and approved the final manuscript.

\section{Funding}

This study was supported by 2014 National Natural Science Foundation of China (Grant number: 31370907) and 2014 Guangdong science and technology plan project (Grant number: 2014A020212483).

\section{Availability of data and materials}

The datasets used during the present study are available from the corresponding author upon reasonable request.

\section{Ethics approval and consent to participate}

This study conformed to the ethics principles of the Declaration of Helsinki and Good Clinical Practice and to the regulatory requirements of China. It also obtained ethical approval from the Institutional Review Board (IRB) of the Third Affiliated Hospital of Sun-Yat-Sen University, IRB of Guangdong General Hospital and IRB of the Eighth People's Hospital of Guangzhou. ([2011]2-49). This study was registered on clinicaltrials.gov on January 31, 2012 and the identifier was NCT01521975. Written informed consent have been obtained from all participants.

\section{Consent for publication}

Not Applicable.

\section{Competing interests}

All authors declare that they have no competing interest.

\section{Author details}

'Department of Infectious Disease, The Third Affiliated Hospital of Sun Yat-sen University, 600 Tianhe Road, Tianhe District, Guangzhou 510630, Guangdong Province, China. ${ }^{2}$ First Department of Liver Disease, Guangzhou Eighth People's Hospital, Guangzhou 510000, Guangdong Province, China. ${ }^{3}$ Department of Infectious Disease, Guangdong General Hospital, Guangzhou 510000, Guangdong Province, China.

Received: 23 August 2020 Accepted: 19 November 2020

Published online: 07 December 2020

\section{References}

1. World Health Organization. March 2015 [cited 2015 May 5].

2. Liaw Y-F, Chu C-M. Hepatitis B virus infection. Lancet. 2009:373:582-92.

3. European Association for the Study of The Liver. EASL clinical practice guidelines: management of chronic hepatitis B virus infection. J Hepatol. 2012;57:167-85.

4. Lavanchy D. Hepatitis B virus epidemiology, disease burden, treatment, and current and emerging prevention and control measures. J Viral Hepat. 2004; 11:97-107.

5. Nash K. Telbivudine in the treatment of chronic hepatitis B. Adv Ther. 2009; 26:155-69.

6. Koumbi L. Current and future antiviral drug therapies of hepatitis B chronic infection. World J Hepatol. 2015;7(8):1030-40.

7. Ke W, Liu L, Zhang C, Ye X, Gao Y, Zhou S, Yang Y. Comparison of efficacy and safety of tenofovir and entecavir in chronic hepatitis B virus infection: a systematic review and meta-analysis. PLoS One. 2014;9:e98865.

8. Liaw Y-F, Kao J-H, Piratvisuth T, Chan H, Chien R-N, Liu C-J, et al. AsianPacific consensus statement on the management of chronic hepatitis $\mathrm{B}$ : a 2012 update. Hepatol Int. 2012;6:531-61.

9. Lok ASF, McMahon BJ. Chronic hepatitis B: update 2009. Hepatology. 2009; 50:661-2.

10. Lee M, Keeffe EB. Hepatitis B: modern end points of treatment and the specter of viral resistance. Gastroenterol Clin N Am. 2011;40:495-505.

11. Gane EJ, Wang Y, Liaw YF, et al. Efficacy and safety of prolonged 3-year telbivudine treatment in patients with chronic hepatitis B. Liver Int. 2011 31(5):676-84.

12. Liaw YF, Gane $E$, Leung N, et al. 2-year GLOBE trial results: telbivudine is superior to lamivudine in patients with chronic hepatitis B. Gastroenterology. 2009;136(2):486-95.
13. Sun J, Xie Q, Tan D, et al. The 104-week efficacy and safety of Telbivudinebased optimization strategy in chronic hepatitis B patients: a randomized, controlled study. Hepatology. 2014;59:1283-92.

14. $\mathrm{AA}$ Lin $\mathrm{CL}$, Yang HC, Kao JH. Hepatitis B virus: new therapeutic perspectives. Liver Int. 2016;36(Suppl 1):85-92.

15. BB Liu Y, Liu L, Peng D, et al. Long-term efficacy and safety of telbivudine as monotherapy and as combination therapy with adefovir dipivoxil in $\mathrm{HBeAg}$ positive chronic hepatitis B patients. Zhonghua Gan Zang Bing Za Zhi. 2014; 22(3):181-4.

16. Chen L, Cheng $C$, Chen B, al e. Cumulative incidence and risk factors of creatine kinase elevation associated with telbivudine. Eur J Clin Pharmacol. 2016;72(2):235-41.

17. D Xu H, Wang Z, Zheng L, et al. Lamivudine/telbivudine-associated neuromyopathy: neurogenic damage, mitochondrial dysfunction and mitochondrial DNA depletion. J Clin Pathol. 2014;67(11):999-1005.

18. Chen Juan E, Hong-wen Z, Deng L, et al. Analysis of telbivudine treatment induced creatine elevation in patients with chronic hepatitis B. Chin Hepatol. 2016;21(5):334-7.

19. Lee HA, Seo YS, Park SW, et al. Hepatitis B surface antigen titer is a good indicator of durable viral response after entecavir off-treatment for chronic hepatitis B. Clin Mol Hepatol. 2016;22(3):382-9.

20. Yuan Q, Song L-W, Liu C-J, et al. Quantitative hepatitis B core antibody leve may help predict treatment response in chronic hepatitis B patients. Gut. 2013;62(1):182-4

21. Fan R, Sun J, Yuan Q, et al. Baseline quantitative hepatitis B core antibody titre alone strongly predicts HBeAg seroconversion across chronic hepatitis $B$ patients treated with peginterferon or nucleos(t)ide analogues. Gut. 2016; 65(2):313-20.

22. Tseng TC, Yu ML, Liu CJ, et al. Effect of host and viral factors on hepatitis B e antigen-positive chronic hepatitis B patients receiving pegylated interferon-a-2a therapy. Antivir Ther. 2011;16(5):629-37.

23. Marcellin $\mathrm{P}, \mathrm{Ahn} \mathrm{SH}, \mathrm{Ma} \mathrm{X}$, et al. Combination of tenofovir disoproxil fumarate and peginterferon $a-2 a$ increases loss of hepatitis $B$ surface antigen in patients with chronic hepatitis B. Gastroenterology. 2016;150(1): 134-144.e10.

24. Chi H, Hansen BE, Guo S, et al. Pegylated interferon alfa-2b add-on treatment in hepatitis B virus envelope antigen-positive chronic hepatitis B patients treated with nucleos(t)ide analogue: a randomized, controlled trial (PEGON). J Infect Dis. 2017;215(7):1085-93.

25. Gane EJ, Deray G, Liaw YF, et al. Telbivudine improves renal function in patients with chronic hepatitis B. Gastroenterology. 2014;146(1):138-46.

\section{Publisher's Note}

Springer Nature remains neutral with regard to jurisdictional claims in published maps and institutional affiliations.

Ready to submit your research? Choose BMC and benefit from:

- fast, convenient online submission

- thorough peer review by experienced researchers in your field

- rapid publication on acceptance

- support for research data, including large and complex data types

- gold Open Access which fosters wider collaboration and increased citations

- maximum visibility for your research: over $100 \mathrm{M}$ website views per year

At BMC, research is always in progress.

Learn more biomedcentral.com/submissions 